\title{
Tüketicilerin Yeşil Ürün Satın Alma Davranışlarının Kuşaklar Bakımından İncelenmesi
}

\author{
DOI: 10.26466/opus.565155 \\ * \\ Pınar Yürük Kayapınar* $^{*}$ Özgür Kayapınar** - Senem Ergan ${ }^{* * *}$ \\ *Dr. Öğr. Üyesi, Trakya Üniversitesi, Uzunköprü Uyg. Bil. Yüksekokulu, Edirne / Türkiye \\ E-Posta: pinaryuruk@trakya.edu.tr \\ ORCID: $0000-0002-7460-6465$ \\ ** Dr. Öğr. Üyesi, Trakya Üniversitesi, Uzunköprü Uyg. Bil. Yüksekokulu, Edirne / Türkiye \\ E-Posta: ozgurkayapinar@trakya.edu.tr \\ ORCID: $\quad$ 0000-0002-2003-5863 \\ *** Dr. Öğr. Üyesi, Çanakkale Onsekiz Mart Üni., Gökçeada Uyg. Bil. Y.O, Çanakkale / Türkiye. \\ E-Posta: senemergan@comu.edu.tr \\ ORCID: $\underline{0000-0002-2155-2643}$
}

Öz

Bilinçli tüketicilerin ve çevreye olan duyarlılıklarının artması, pazarlama literatüründe de yeni yaklaşımların ortaya çıkmasını sağlamıştır. Bu yaklaşımlardan biri de çevre hassasiyetini konu alan yeşil ürün kavramıdır. Yeşil ürün çevreye, doğal kaynaklara zarar vermeyen, să̆̆l̆̆̆ olumsuz yönde etkilemeyen ve geri dönüşümü destekleyen ürünlerdir. Tüketicilerin farklı demografik özelliklere sahip olması, onların istek ve ihtiyaçlarının farklılaşmasına neden olmakta, bu nedenle yeşil ürünlere yönelik düşünceleri de değiş̧ikliğe uğramaktadır. Bu nedenle bu çalışmada, yeşil ürün satın alma davranışları üzerine odaklanılmaktadır. Demografik özelliklerin farklılaştığı X, Y ve Z kuşağı tüketicilerin yeşil ürün satın almaya yönelik davranışları incelenmektedir. Bu amaç doğrultusunda $X, Y$ ve Z kuşağı tüketicilerden yüz yüze anket yöntemi ile toplam 435 anket toplanmıştır. Elde edilen verilere SPSS 25.0 istatistik programı ile birlikte frekans analizi, $t$ testi ve ANOVA testleri uygulanmıştır. Çıkan sonuçlara göre; kadınların erkeklere göre, evli olan katılımciların bekar katılımcılara göre yeşil ürün satın almada daha duyarlı oldukları ortaya çıkmıştır. Ayrıca, kuşaklara göre bakıldı̆̆ında ise, X kuşă̆g katılımcıları, Y ve $\mathrm{Z}$ kuşaklarına göre yeşil ürün konusunda daha hassas davranmakta ve yeşil ürün satın alma konusunda daha istekli olmaktadırlar.

Anahtar Kelimeler: X-Y ve Z Kuşağı, Yeşil Ürün, Yeşil Tüketim, Yeşil Ürün Satın Alma. 


\title{
Investigation of Green Product Purchasing Behaviors of Consumers from the Generation
}

\begin{abstract}
Increasing conscious consumers and environmental sensitivity has led to the emergence of new approaches in marketing literature. One of these approaches is the concept of green product which is about environmental sensitivity. With this concept, green product is that do not harm the natural resources, affect the health in the negative direction and support the recycling gain importance. The fact that consumers have different demographic characteristics causes differentiation of their wishes and needs, for this reason, the thoughts on green products are also changing. For this reason, this study focuses on green product purchasing behaviors. The behavior of $X, Y$ and $Z$ generation consumers who have different demographics to buy green products is examined. For this purpose, a total of 435 questionnaires were collected by face-to-face survey method from $X, Y$ and $Z$ generation consumers. Frequency analysis, $t$ test and ANOVA tests were applied to the obtained data with SPSS 25.0 statistical program. According to the results; it is found that women are more sensitive than men and that married participants are more likely to buy green products than single participants. In addition, when viewed from generation to generation, $X$ generation participants are more sensitive to green products than $Y$ and $Z$ generations and are more willing to buy green products.
\end{abstract}

Keywords: Generation, X, Y and Z Generation, Green Product, Green Consumption, Green Product Purchase. 


\section{Giriş}

İşletme sayılarının ve ürettikleri ürünlerin artışı, tüketicilerin işletmeleri daha ayrıntılı bir şekilde analiz etmelerine neden olmaktadır. İşletmelerin gerçekleştirdikleri faaliyetler tüketiciler tarafından izlenmekte ve tüketiciler bu faaliyetlere göre işletmeleri konumlandırmaktadır. Bu nedenle işletmelerin yaptıkları ya da yapacakları yanlış bir davranış tüketicilerin tutumlarının hemen değişmesini sağlamaktadır.

Günümüzde tüketicilerin en çok önem verdikleri konulardan biri işletmelerin çevresel duyarlılı̆̆ıdır. Çevreye duyarlı olmayan, insan veya hayvan sağlığını tehlikeye atan, kirliliğe karşı koymayan kısacası yeşil dostu faaliyetler gerçekleştirmeyen işletmeler tüketiciler tarafından hemen terkedilebilmektedir. Bu durum işletmelerin pazarlama faaliyetlerinde doğrudan etkili olmaktadır. Pazarlamanın da doğrudan karşı karşıya kaldığı bu problem ile birlikte işletmeler çevreye duyarlı bir tüketici kimliği oluşturmanın yollarını aramaya başlamışlardır. Bir işletme ne kadar çok yeşil dostuysa tüketici kimlikleri de çevreye duyarlı bir şekilde gelişebilmektedir. Bu nedenle yeşil ürün, yeşil pazarlama ya da yeşil ürün satın alma davranışları konusunda yapılan çalışmalar önemlilik arz etmektedir.

$\mathrm{Bu}$ çalışmanın da amacı, kuşaklara göre yeşil ürün satın alma davranışlarının farklılık gösterip göstermediğini incelemektir. Bu amaç doğrultusunda X, Y ve Z kuşakları seçilmiştir. 1927 ile 1945 yılları arasında doğanlar gelenekselci kuşak, 1946-1964 yılları arasında doğanlar bebek patlaması (Baby Boomer) (Castellano, 2014), 1965 ile 1979 yılları arasında doğanlar X kuşağı (Alwin, 2002), 1980-1999 Y kuşağı (Lower, 2008, s.80) ve 2000'den sonra doğanlar ise Z kuşağı (Altuntuğ, 2012: 206) olarak adlandırılmaktadır.

\section{Literatür Taraması}

\section{Yeşil Pazarlama, Yeşil Ürün ve Yeşil Ürün Satın Alma Davranışları}

Kirliliğe ve enerji korunmasına yönelik olarak başlatılan 1960 ekoloji hareketi, çevresel sorunlarından rekabet avantajına kadar birçok konuya değinmektedir. 'Yeşil' konusunun ele alınması ve akademik araştırma- 
ların başlaması da bu zamana denk gelmektedir. 25-30 yıl önceki bu çabalar ileride yapılması planlanan araştırmalar için uygun zemin hazırlamıştır. 1980'lerde çevresel endişeler altında bu konu akademik olarak yeniden tanımlanmış, 1990'larda ise çevresel kaygılarda büyük bir artış yaşanmış ve günümüze kadar artarak devam etmiştir (Straughan vd., 1999, s.558).

Son yıllarda pazarlama teorisinde ve pazarlamanın pratik dünyasında, 'çevre dostu' ya da 'yeşil ürün' kavramları, önemli bir trend haline gelmiştir. Yeşile doğru gidiş; insanlar, kar ve gezegen üçlüsüne önemli bir katkıda bulunmakta, işletme kültüründe ve tüketicilerin çevresel inançları ve tutumları doğrultusunda stratejik kararlarda önemli değişiklikler yapılmasını gerektirmektedir. Tüketicilerin çoğu satın alma davranışlarında değişikliğe giderek, çevresel sorunları göz önünde bulundurmakta ve genellikle ekolojik olarak uyumlu ürünleri (biyolojik olarak doğada kendiliğinden kaybolan) satın almak istemektedirler (Samarasinghe vd., 2013, s.173) ve bu satın alma anlık bir kazançtan çok geleceğe yönelik sonuçlar doğurmaktadır (Kaufmann vd., 2012, s.51). Bu nedenle pazarlamada hem teoride hem de pratikte önemle üzerinde durulması gereken konuyu oluşturmaktadır.

Yeşil pazarlama, tüketicilerin istek ve ihtiyaçlarını karşılamak ve işletmenin hedeflerine ulaşmayı sağlamak amacıyla çevreye duyarlı ürünlerin tasarlanmasından itibaren ürünün kullanım sonrasına kadar uzanan süreçleri kapsayan planlı pazarlama faaliyetleridir (Çetinkaya vd., 2017, s.290).

Bir başka tanıma göre ise yeşil pazarlama, insan ihtiyaç ve isteklerini karşılamayı amaçlayan her türlü değişimin üretilmesi ve kolaylaştırılması için doğal çevreye en az zarar vermek üzere tasarlanan faaliyetlerin oluşturulmasıdır. İşletmelerin yeşil pazarlama faaliyetlerini gerçekleştirmesi ve önem vermesinin beş temel nedeni söz konusudur (Polonsky, 1995):

- Hükümet organları işletmeleri daha yeşil ürün konusunda daha sorumlu olmak için zorlamaktadır.

- İşletmeler, yeşil pazarlamayı amaçlarına ulaşmak için kullanılabilecek bir firsat olarak algılamaktadır.

- İşletmeler daha çok sosyal sorumlu olmanın ahlaki bir yükümlülük olduğuna inanmaktadır. 
- Rakiplerin çevresel faaliyetleri, onları yeşil pazarlama faaliyetlerinde bulunmaları için zorlamaktadır.

- İşletmelerin atık ürünleri, üretim süreçlerini ve ürünlerini yeniden üretmek konusunda zorlamaktadır.

Yeşil pazarlamanın gelişimi, üç farklı aşamada incelenmektedir. Birincisi, zararlı ürünlere olan bağımlılığı azaltmaya çalışan ekolojik pazarlama; çevresel zararı azaltmaya çalışan çevresel pazarlama; sürdürebilir bir ekonomik düzen yaratmak için üretim ve tüketim maliyetlerini karşılamaya çalışan sürdürülebilir pazarlamadır (Gedik vd., 2014, s.2).

İşletmeler yeşil pazarlama faaliyetlerini gerçekleştirdikleri yeşil ürünlerini pazarda konumlandırabilmek için iki aşamadan geçmektedirler. Birincisi, işletmeler önce pazarı çevreci satın alma davranışlarına göre bölümlere ayırmall, ikincisi ise, 'daha yeşil' olan tüketici bölümlerini hedef pazar olarak seçmelidirler (Bohlen vd., 1993; Schlegelmilch vd., 1996, s.35). Bu konumlandırma faaliyetlerini gerçekleştirebilmek için yeşil ürün ve hizmetlerin hedef pazar olarak seçimi yapılırken işletmeler bazı faktörleri göz önünde bulundurmak zorundadırlar (Straughan vd., 1999, s.562):

- Pazar bölümünün büyüklüğü,

- Pazar bölümünün erişilebilirliği,

- Bölümü tanıma kolaylığ

- Stratejik/Operasyonel etkinlik ve

- Bölümün istikrarı.

Yeşil ürün satın almanın temel amaçları, sosyal ve toplumsal faaliyetlere dahil olmak, gerçek yeşil davranış ile çevreyi korumak ve sosyal, yasal, politik ve çevre dostu çalışmalara katılımı sağlamaktır (Ajzen vd., 1980). Bir ürünün yeşil ürün olarak ifade edilebilmesi için aşağıdaki özelliklere sahip olması gerekmektedir. Yeşil ürün (Moisander, 2007):

- İnsan ve hayvan sağlığı için tehlike içermemektedir.

- Üretim, kullanım sırasında çevreye zarar vermemektedir.

- Üretim ve kullanım sırasında enerji ve diğer kaynakları orantısız bir şekilde kullanmamaktadır.

- Gereksiz atıklara neden olmamaktadır.

- Hayvanlara ya da diğer canlılara zarar vermemektedir.

- Zararlı maddeler kullanılmamaktadır. 


\section{Yeşil Pazarlama, Yeşil Ürün ve Yeşil Ürün Satın Alma Davranışları Üzerine Yapılan Çalışmalar}

Geçmiş yıllarda yeşil pazarlama, yeşil ürün veya yeşil ürün satın alma davranışları üzerinde yapılan çalışmalara bakıldığında çalışmaların bir kısmında benzer bir kısmında ise farklı sonuçların ortaya çıktığ 1 görülmektedir. $\mathrm{Bu}$ çalışmaların bazıları ve elde edilen sonuçları şu şekildedir:

Straughen vd., (1999, s.558)'in Amerika'da üniversite öğrencileri üzerinde yaptıkları çalışmasında, özellikle demografik özelliklerin üniversite öğrencilerinin yeşil ürün hakkındaki duyarlılıklarını etkilediği bulunmuştur.

Schaper (2002)'in Avustralya'da yaptığı araştırmada ise, 154 ilaç perakendecisinin yeşil ürün hakkında olumlu düşünmelerine rağmen bu davranışlarını, satın alma kararlarına yansıtamadıkları incelenmiştir.

Michaud v.d., 2011 yılında yaptığı çalışmada, tüketicilerin çevresel sorunları gün geçtikçe daha çok fark ettikleri, özellikle organik ürünlere daha fazla para ödemeye razı oldukları ve çevreyi kirleten mal ya da hizmetleri satın almak istemedikleri, satın alma aşamasında çevresel farkındalıklarını uygulayabildikleri ortaya çıkmıştır.

Braimah vd., (2011)'nin tüketicilerin yeşil pazarlama farkındalıklarını ölçmeye çalıştıkları ve 200 katılımcı üzerinde gerçekleştirdikleri çalışmalarında ise, Ganalı tüketicilerin yeşil pazarlama bilinçlerinin çok düşük seviyede oldukları, çevresel sorunların satın alma kararlarında etkisi olmadığı ve genellikle bu ürünleri satın almada fiyat konusunun en önemli endişelerinin olduğu bu durumun da tüketicilerin satın alma kararlarını etkiledikleri incelenmiştir.

Samarasinghe v.d., (2013, s.172), 238 tüketici üzerinde yaptıkları çalışmalarında, çevre bilincinin yeşil satın alma davranışları üzerinde herhangi bir etkisinin olmadığı belirlenmiştir.

Yıldırım vd., 2015 yılında Sakarya Üniversitesi'nde 432 öğrenci üzerinde yaptıkları çalışmada ise, öğrencilerin çevre duyarlılığı ve gelirlerinin yeşil ürün satın alma davranışlarında etkili olduğu, gelir düzeyi arttıkça yeşil ürün satın alma isteklerinin de arttığı ortaya çıkmıştır. 
Benzer bir çalışma olan Alkaya v.d, (2016, s.121) Ordu Üniversitesi öğrencileri üzerinde yaptığı çalışmada da, çevresel duyarlılığın yeşil ürün satın almaya etkisi olduğu ortaya çımıştır.

Üniversite öğrencileri üzerinde yapılan bir başka çalışma ise, Üstündağlı vd., 2015 yılında yaptıkları çalışmasıdır. Bu çalışma 539 lisans öğrencisi üzerinde yapılmış ve yeşil farkındalığın genç tüketicilerinin yeşil satın alma davranışlarını göstermeyebileceği ve fiyat faktörünün yeşil satın alma kararını vermede önemli bir değişken olduğu tespit edilmiştir.

Gazi Üniversitesi'nde 225 üniversite öğrencisi üzerinde yapılan çalışmada ise, öğrencilerin ebeveynlerinin meslekleri ile yeşil satın alma davranışları arasında önemli bir ilişki olduğu, öğrencilerin çevresel konulara duyarlı olmalarına rağmen bu davranışlarını satın alma davranışlarına gösteremedikleri incelenmiştir (Tunç Hussein vd., 2010, s.50).

\section{Metodoloji}

\section{Araştırmanın Amacı ve Hipotezleri}

Araştırmanın amacı, farklı davranışlar sergileyen $X, Y$ ve $Z$ kuşağı tüketicilerinin yeşil ürün satın alma davranışları (YSA) arasında fark olup olmadığını incelemektir. Bu amaç doğrultusunda, araştırmaya katılan tüketicilerin cinsiyetleri, medeni durumları, eğitim durumları ve gelirleri ile ve en önemlisi tüketicilerin içinde bulundukları kuşak ile yeşil ürün satın alma davranışları arasındaki farklılık veya benzerlikler belirlenecektir. Bu amaçlara göre oluşturulan hipotezler ise şu şekildedir:

- H1: Yeşil ürün satın alma, katılımcıların cinsiyetlerine göre farklılık göstermektedir.

- $\mathrm{H}_{2}$ : Yeşil ürün satın alma, katılımcıların medeni durumlarına göre farklılık göstermektedir.

- $\mathrm{H}_{3}$ : Yeşil ürün satın alma, katılımcıların eğitim durumlarına göre farklılık göstermektedir.

- H4: Yeşil ürün satın alma, katılımcıların aylık gelir durumlarına göre farklılık göstermektedir.

- H5: Yeşil ürün satın alma, katılımcıların içerisinde yer aldığı kuşaklara göre farklılık göstermektedir. 


\section{Verilerin Toplanması ve Ölçeği}

Araştırmanın ölçeğinde yer alan değişkenler farklı kişiler tarafından farklı makalelerde kullanılan, orijinali İngilizce olan ölçeklerdir. Yeşil ürün satın alma ölçeğinde yer alan ifadeler, bilimsel yöntemler temel alınarak geliştirilmiş, geçerlilik ve güvenilirlikleri yapılan araştırmalar ile ölçülmüş ve kullanılabilir olduğu tespit edilmiş olup Türkçeye çevrilerek örnekleme göre uyarlanmış ifadelerdir. Yeşil ürün satın alma davranışı ölçeği, Keleş (2007) tarafından farklı çalışmaları bir araya getirerek yapılan çalışmadan faydalanılarak oluşturulmuştur.

Yeşil ürün satın alma davranışı ölçeğindeki ifadeler, 1'den 5'e kadar 1=Kesinlikle Katılmiyorum, 5=Kesinlikle Katılyyorum şeklinde Likert Ölçeği'ne göre hazırlanmıştır. Örneklemi belirlerken, kolayda örneklem yönteminden faydalanılmıştır. Araştırma, Tekirdağ ilinde uygulanmış, eksik verilerin bulunduğu anketler çıarılarak, kullanılabilir 435 anket analizlerde kullanılmıştır.

\section{Verilerin Analizi ve Sonuçlar}

Anket uygulamasindan elde edilen veriler, SPSS 25.0 istatistik paket programı yardımıyla analiz edilmiştir. Araştırmanın amacı doğrultusunda ilk olarak araştırmaya katılan katılımcıların demografik özelliklerinin belirlenmesi amaciyla frekans analizi, daha sonra oluşturulan hipotezlere doğrultusunda, T-testi ve ANOVA analizleri yapılarak farklılıklar incelenecektir.

Tablo 1 incelendiğinde, ankete cevap veren katılımcıların, cinsiyetlerine göre \%54,3 ile kadın katılımcıların, medeni durumlarına göre $\% 58,6$ 'sının bekar ve eğitim durumlarına göre $\% 41,5$ 'inin lise mezunu olduğu tespit edilmiştir. Katılımcıların doğum yıllarına göre \%21,8'inin 1965-1979 yılları arasında doğduğu ve X kuşağı içerisinde yer aldığ1, \%56,4'ünün 1980-1999 yılları arasında doğduğu ve $Y$ kuşağ 1 içerisinde yer aldığı ve \%21,8'inin 2000 ve sonrasında doğduğu ve $Z$ kuşağ içerisinde yer aldığı gözlenmektedir. Yine Tablo 1'e göre katılımcıların \%51'inin yani büyük bir çoğunluğunun gelir durumunun 3000 TL ve altında olduğu saptanmiştır. 
Tablo 1: Katılımcıların Demografik Özelliklerine Göre Dağılımı

\begin{tabular}{llll}
\hline & & $\begin{array}{l}\text { Frekans } \\
\text { (f) }\end{array}$ & $\begin{array}{l}\text { Yüzde } \\
\text { (\%) }\end{array}$ \\
\hline Cinsiyet & Kadın & 236 & 54,3 \\
& Erkek & 199 & 45,7 \\
\hline Medeni Durum & Bekar & 255 & 58,6 \\
& Evli & 180 & 41,4 \\
\hline Eğitim Durumu & İlköğretim & 49 & 11,3 \\
& Lise & 180 & 41,5 \\
& Ön Lisans & 73 & 16,8 \\
& Lisans & 88 & 20,2 \\
& Yüksek Lisans & 25 & 5,7 \\
& Doktora & 20 & 4,6 \\
\hline Doğum Yılı & 1965-1979 (X kuşağı) & 95 & 21,8 \\
& 1980-1999 (Y kuşağı) & 245 & 56,4 \\
& 2000 ve sonrası (Z kuşağı) & 95 & 21,8 \\
\hline Aylık Gelir & 3000 TL ve Altı & 222 & 51,0 \\
& 3001-5000 TL & 107 & 24,6 \\
& 5001-7000 TL & 68 & 15,6 \\
& 7001-9000 TL & 20 & 4,6 \\
& 9001-11000 TL & 7 & 1,6 \\
& 11001 TL ve Üstü & 11 & 2,5 \\
\hline
\end{tabular}

Ölçekte elde edilen verilerin skorları aritmetik ortalama kullanılarak hesaplanmıştır. Elde edilen skorların demografik özellikler ile yeşil ürün satın alma ilişkilerinin ve bir farklılık yaratıp yaratmadığının değerlendirilmesi için verilerin normal dağılımı da göz önüne alınarak T-testi ve ANOVA testi uygulanmıştır.

Tablo 2: Yeşil Ürün Satın Alma ile Cinsiyet ve Medeni Durumları Arasındaki İlişsinin T-Testi Sonuçları

\begin{tabular}{llllllll}
\hline & & & N & Ortalama & $\begin{array}{l}\text { Std. } \\
\text { Sapma }\end{array}$ & t & $\begin{array}{l}\text { Anlamlılık } \\
\text { Seviyesi }\end{array}$ \\
\hline \multirow{4}{*}{ YSA } & Cinsiyet & Kadın & 236 & 3,707 & 0,622 & 2,713 & 0,007 \\
\cline { 2 - 8 } & Medeni & Evkek & 199 & 3,544 & 0,627 & & \\
& Durum & Bekar & 255 & 3,530 & 0,679 & & 0,000 \\
\hline
\end{tabular}

Tablo 2 incelendiğinde, katılımcların cinsiyet ve medeni durumlarına göre T-Testi sonuçlarının anlamlılığının YSA açısından 0,05'ten küçük 
olduğu gözlenmiştir. Dolayısıyla $\mathrm{H}_{1}$ ve $\mathrm{H}_{2}$ hipotezleri YSA için kabul edilmektedir.

Cinsiyetlerine göre kadın katılımcıların $(3,707)$ ortalamalarının, erkek katılımcların ortalamalarına $(3,544)$ göre azda olsa fazla olduğu ve yeşil ürün satın alma konusunda farklılık gösterdiği gözlenmektedir.

Medeni durumlarına göre evli katılımcıların ortalamalarının $(3,779)$ bekar katılımciların ortalamalarına $(3,530)$ göre daha yüksek olduğu dolayısıyla yeşil ürün satın alma konusunda evli olanların daha fazla eğilimi olduğu gözlenmektedir.

Tablo 3: Yeşil Ürün Satın Alma ile Katılımcıların Ĕ̆itim Durumları, Aylık Gelirleri ve Kuşakları Arasındaki İlişkinin ANOVA Testi Sonuçları

\begin{tabular}{|c|c|c|c|c|c|c|c|}
\hline & & & $\begin{array}{l}\text { Kareler } \\
\text { Toplamı } \\
\end{array}$ & sd & $\begin{array}{l}\text { Kareler } \\
\text { Ortalaması } \\
\end{array}$ & F & $\begin{array}{l}\mathbf{P} \\
\text { Değeri }\end{array}$ \\
\hline \multirow{9}{*}{ YSA } & \multirow{3}{*}{$\begin{array}{l}\text { Eğitim } \\
\text { Durumları }\end{array}$} & Gruplar Arası & 2,972 & 5 & 0,594 & \multirow[t]{3}{*}{1,513} & \multirow[t]{3}{*}{0,184} \\
\hline & & Gruplar İçi & 168,551 & 429 & 0,393 & & \\
\hline & & Toplam & 171,523 & 434 & & & \\
\hline & \multirow{3}{*}{$\begin{array}{l}\text { Aylik } \\
\text { Gelir }\end{array}$} & Gruplar Arası & 1,545 & 5 & 0,309 & \multirow[t]{3}{*}{0,780} & \multirow[t]{3}{*}{0,565} \\
\hline & & Gruplar İçi & 169,978 & 429 & 0,396 & & \\
\hline & & Toplam & 171,523 & 434 & & & \\
\hline & \multirow{3}{*}{$\begin{array}{l}\mathrm{X}, \mathrm{Y}, \mathrm{Z} \\
\text { Kuşakları }\end{array}$} & Gruplar Arası & 7,268 & 2 & 3,634 & \multirow[t]{3}{*}{9,558} & \multirow[t]{3}{*}{0,000} \\
\hline & & Gruplar İçi & 164,255 & 432 & 0,380 & & \\
\hline & & Toplam & 171,523 & 434 & & & \\
\hline
\end{tabular}

Tablo 3'e göre katılımcıların eğitim durumları ve aylık gelirlerine göre ANOVA testinin anlamlılıkların 0,05'ten büyük olmasından dolayı $\mathrm{H}_{3}$ ve $\mathrm{H}_{4}$ reddedilmektedir. Dolayısıyla yeşil ürün satın almanın katılımcıların eğitim durumları ve aylık gelirlerine göre anlamlı bir farklılık göstermediği belirlenmiştir.

Yeşil ürün satın alma konusunda bireylerin kuşakları arasındaki farklılığın gösterildiği Tablo 3'te anlamlılığın 0,05'ten küçük olduğu gözlenmiş ve $\mathrm{H}_{5}$ kabul edilmiştir, yani yeşil ürün satın alma konusunda katılımcıların kuşakları arasında anlamlı bir farklılık vardır. Bu farklılığın hangi kuşaklar arasında olduğunun tespit edilmesi için verilere TukeyHSD Post-Hoc testi uygulanmış, testin sonucuna göre; $X$ kuşağ katılımcların ortalamalarının $(3,869)$, Y kuşağ $1(3,590)$ ve $Z$ kuşağının $(3,505)$ ortalamalarına göre daha büyük olduğu gözlenmiştir. Başka bir 
ifade ile $X$ kuşağı katılımcılar, yeşil ürün satın alma konusunda $Y$ ve $Z$ kuşağ 1 katılımcılara göre daha eğilimlidirler denilebilmektedir.

\section{Sonuç}

İçinde bulunduğumuz günümüz şartları ile birlikte tüketicilerin çevreye duyarlılıklarının artması, işletmelerin faaliyetlerini bu doğrultuda geliştirmelerini sağlamıştır. Bu nedenle canlıların sağlıklarını tehlikeye sokacak, çevreyi kirletecek, kaynakların hızlı bir şekilde tükenmesine sebep olabilecek herhangi bir davranış hemen karşı tutumun gelişmesine neden olmakta, işletmeler de bu durumdan kaçınarak yeşil dostu faaliyetlerde bulunmaktadırlar.

Tüketicilerin yeşil dostu olmaları içinde bulundukları duruma, demografik özelliklerine, ekonomik durumlarına göre değişmektedir. Bu nedenle bu çalışmada da farklı kuşaklarda yer alan dolayısıyla farklı davranışlarda bulunan tüketicilerin yeşil ürüne ve yeşil ürün satın almaya bakış açılarının nasıl olduğu açılanmaya çalışılmıştır. Elde edilen sonuçlar genel olarak beklenilen sonuçlardır. $\mathrm{Bu}$ sonuçlara göre, cinsiyetlerine bakıldığında kadın katılımcıların $(3,707)$ ortalamalarının, erkek katılımcıların ortalamalarına $(3,544)$ göre fazla olduğu ve yeşil ürün satın alma konusunda farklılık gösterdiği gözlenmektedir. Medeni durumlarına göre evli katılımcıların ortalamalarının $(3,779)$ bekar katılımcların ortalamalarına $(3,530)$ göre daha yüksek olduğu dolayısıyla yeşil ürün satın alma konusunda evli olanların daha fazla eğilimi olduğu gözlenmektedir. Dolayısıyla $\mathrm{H}_{1}$ ve $\mathrm{H}_{2}$ hipotezleri kabul edilmektedir. Katılımcıların eğitim durumları ve aylık gelirlerine göre ANOVA testinin anlamlılıkların 0,05'ten büyük olmasından dolayı $\mathrm{H}_{3}$ ve $\mathrm{H}_{4}$ reddedilmektedir. Dolayısıyla yeşil ürün satın almanın katılımcıların eğitim durumları ve aylık gelirlerine göre anlamlı bir farklılık göstermediği belirlenmiştir. X, Y ve Z kuşaklarının yeşil ürün satın alma davranışlarının farklılık gösterip göstermediği konusunda yapılan analizlerde ise, kuşaklar arasındaki farklılığın anlamlılığının 0,05'ten küçük olduğu gözlenmiş ve $\mathrm{H}_{5}$ kabul edilmiştir, yani yeşil ürün satın alma konusunda katılımcıların kuşakları arasında anlamlı bir farklılık vardır. Başka bir ifade ile $X$ kuşağı katılımcılar, yeşil ürün satın alma konusunda $Y$ ve $Z$ kuşağı katılımcılara göre daha eğilimlidirler. 


\title{
EXTENDED ABSTRACT
}

\section{Investigation of Green Product Purchasing Behaviors of Consumers from the Generation}

\author{
Pınar Yürük-Kayapınar - Özgür Kayapınar - Senem Ergan \\ Trakya University, Çanakkale 18 Mart University
}

The increase in the number of companies and the products, which they produce, has changed the preferences of consumers.Increasing conscious consumers and environmental sensitivity has led to the emergence of new approaches in marketing literature. One of these approaches is the concept of green product which is about environmental sensitivity. With this concept, green product is that do not harm the natural resources, affect the health in the negative direction and support the recycling gain importance. In order to show their environmental awareness to consumers and to do something beneficial to their health, companies have been in search of producing these products. The wrong behaviors, that the companies do or will do, will change the attitudes of the consumers immediately.The fact that consumers have different demographic characteristics causes differentiation of their wishes and needs, for this reason, the thoughts on green products are also changing. Therefore, studies on green product, green marketing or green product buying behaviors are important. For this reason, this study focuses on green product purchasing behaviors.

Demographic factors are one of the factors that have a significant effect on the consumers' purchasing objectives.. The behavior of $\mathrm{X}, \mathrm{Y}$ and $\mathrm{Z}$ generation consumers who have different demographics to buy green products is examined. For this purpose, a total of 435 questionnaires were collected by face-to-face survey method from $X, Y$ and $Z$ generation consumers. The survey was conducted in Tekirdağ. Frequency analysis, $t$ test and ANOVA tests were applied to the obtained data with SPSS 25.0 statistical program. T-test and ANOVA test were applied by taking into consideration the normal distribution of the data in order to evaluate whether the 
scores obtained made a difference between the demographic characteristics and the purchase of green products.

First, the participants' green product purchase behaviors according to gender and marital status were examined. According to the t-test, gender and marital status of the participants were found to be an important variable in green product buying behaviors. Because, according to gender, the average of female participants $(3,707)$, the average of male participants $(3,544)$ was found to be slightly higher than the average. It is observed that female participants differ in purchasing green products compared to male participants. Female participants are more willing to buy green products. According to the results of t-test according to marital status, married participants give more importance to buying green products than single participants. According to their marital status, the average of married participants $(3,779)$ was higher than the average of single participants $(3,530)$. Thus, $\mathrm{H} 1$ and $\mathrm{H} 2$ hypotheses are accepted.

Secondly, the participants' educational status, monthly income and their buying behaviors according to their generations were examined. In the results of the ANOVA test, according to the educational level and monthly income of the participants, it was determined that the purchase of green products did not show a significant difference according to the educational status and monthly income of the participants. $\mathrm{H} 3$ and $\mathrm{H} 4$ are rejected. However, when the green product purchase behaviors of the participants are examined, it is observed that there is a significant difference between X, Y, and Z generations. TukeyHSD Post-Hoc test was applied to the data in order to determine the differences between these generations. According to the results of this test, The average of generation $X(3,869)$, generation $Y(3,590)$ and generation $Z(3,505)$ were higher than the average. That is, the $\mathrm{H} 5$ hypothesis was accepted. In other words, it can be said that generation $X$ participants are more inclined to buy green crops than generation $\mathrm{Y}$ and $\mathrm{Z}$ participants.

Today, consumers prefer to buy and use products of enterprises that do not harm human and animal health, do not use natural resources disproportionately, do not cause unnecessary waste, do not use harmful substances, give importance to recycling and aim for social responsibility. Therefore, the concepts of ürün green product, green consumer, green marketing tedir are becoming more and more important. This importance 
varies from consumer to consumer and as can be seen from the results of this study, one of the most important factors affecting this change is demographic factors. Companies need to pay attention to the results of these studies in order to examine consumers' green product buying behaviors. It is thought that the study will be both a theoretical and practical guide and an important resource. In the future, a study with different participants and different scales at a different location may lead to different results. Therefore, the results of this study include the place where the research was conducted and the participants.

\section{Kaynakça / References}

Ajzen, I. ve Fishbein, M. (1980). understanding attitudes and predicting social behavior, NJ:Prentice-Hall, Englewood Cliffs.

Alkaya, A., Çoban, S., Tehci, A. ve Ersoy, Y. (2016). Çevrsel duyarlılığın yeşil ürün satın alma davranışına etkisi: Ordu Üniversitesi örneği. Erciyes Üniversitesi İktisadi ve İdari Bilimler Fakültesi Dergisi, 47, 121134.

Altuntuğ, N. (2012). Kuşaktan kuşağa tüketim olgusu ve geleceğin tüketici profili. Organizasyon ve Yönetim Bilimleri Dergisi, 4(1), 203-212.

Alwin, D. F. (2002). Generations X, Y and Z: Are they changing America, American Sociological Association, Contexts, 42(1), 42- 51.

Bohlen, G. M., Schlegelmilch, B.B. ve Diamantopoulos, A. (1993). Measuring ecological concern: A multi-construct perspective. Journal of Marketing Management, 9(4), 415-430.

Braimah, M. ve Tweneboah-Koduah, E. Y. (2011). An exploratory study of the impact of green brand awareness on consumer purchase decisions in Ghana. Journal of Marketing Development and Competitiveness, 5(7), 11-18.

Castellano, G. W. (2014). Practices for engaging the 21st century workforce: Challenges of ta- lent management in a changing workplace, New Jersey: Pearson Education.

Çetinkaya, C. ve Özceylan E. (2017). A survey on university students' attitudes on green products: A case study in Gaziantep University. Gaziantep University Journal of Social Sciences, 16(1), 289-302. 
Gedik, T., Kurutkan, M. N. ve Çil, M. (2014). Yeşil pazarlama algısı ve yeşil satın alma davranış1: Düzce Üniversitesi örneği. Ormancılık dergisi, 10(1), 1-13.

Kaufmann, H. R., Panni, M. F. A. K. ve Orphanidou, Y. (2012). Factors affecting consumers' green purchasing behaviour: An integrated conceptual framework. Amfiteatru Economic, 14(31), 50-69.

Keleş, C. (2007). Yeşil pazarlama tüketicilerin yeşil ürünleri tüketme davranışları ve yeşil ürünlerin tüketiminde kültürün etkisi ile ilgili bir uygulama, Yayımlanmamış Yüksek Lisans Tezi Çukurova Üniversitesi Sosyal Bilimler Enstitüsü, Adana.

Lower, J. (2008). Brace yourself here comes generation Y. Critical Care Nurse, 28(5), 80-85.

Michaud, C. ve Llerena D. (2011). Green consumer behaviour: An experimental analysis of Willingness to pay for remanufactured products. Business Strategy and The Enviornment, 20, 408-420.

Moisander, J. (2007). Motivational complexity of green consumerism. International Journal of Consumer Studies, 31, 404-409.

Polonsky, M. J. (1995). A stakeholder theory approcah to designing environmental marketing strategy. Journal of Business $\mathcal{E}$ Industrial Marketing, 10(3), 29-46.

Samarasinghe, G. D. ve Samarasinghe, D. S. R. (2013). Green decisions: consumers' environmental beliefs and green pruchasing behaviour in Sri Lankan context. Int. J. Innovation and Sustainable Development, 7(2), 172-184.

Schaper, M. (2002). Predictors of green purchasing in Western Australian pharmacies. International Small Business Journal, 20 (3), 235-251.

Schlegelmilch, B. B., Bohlen, G. M. ve Diamantopoulos, A. (1996). The link between green purchasing decisions and measures of environmental consciousness. European Jorunal of Marketing, 30(5), 25-55.

Straughan, R. D. ve Roberts, J. A. (1999). Environmental segmentation alternatives: A look at green consumer behaviour in the new millennium. Journal of Consumer Marketing, 16(6), 558-575.

Tunç-Hussein, A. ve Cankül, D. (2010). Üniversite öğrencilerinin yeşil pazarlama faaliyetleri kapsamında çevreye ilişkin davranışlarını belirlemeye yönelik bir araştırma. Ticaret ve Turizm Eğitim Fakültesi Dergisi, 1, 50-67. 
Üstündağlı, E. ve Güzeloğlu, E. (2015). Gençlerin yeşil tüketim profili: Farkındalik, tutum ve davranış pratiklerine yönelik analiz. Global Media Journal TR Edition, 5(10), 341-362.

Yıldırım, E. ve Türkmen, M. (2015). Çevre duyarlılığı ve gelirin yeşil ürün satın alma duyarlılığı üzerindeki etkisi. 20. Ulusal Pazarlama Kongresi, bildiriler içinde (387-397), 10-13 Nisan, Eskişehir.

\section{Kaynakça Bilgisi / Citation Information}

Yürük-Karapınar, P., Kayapınar, Ç. ve Ergan, S. (2018). Tüketicilerin yeşil ürün satın alma davranışlarının kuşaklar bakımından incelenmesi. OPUS-Uluslararası Toplum Araştırmaları Dergisi, 11(18), 2055-2070. DOI: 10.26466/opus.565155 